\title{
Surgical Treatment of Idiopathic Clubfoot
}

\author{
Edvin Selmani MD, MSc, $\mathbf{P h D}^{1}$, Valbona Selmani $\mathbf{M D}^{2}$ \\ ${ }^{1}$ University Service of Orthopaedic and Traumatology \\ ${ }^{2}$ University Hospital Center Mother Theresa, Tirana, Albania
}

\begin{abstract}
Introduction: Treatment of idiopathic clubfoot has evolved over the years through different changes where surgery and conservative treatment have been competing each other. Prevention of recurrence is the main challenge that each method faces. Goal: This study presents the functional results of surgical treatment of idiopathic clubfoot with posteromedial release (Turco). Material and Method: We followed up for a minimum of 5 years, 56 operated clubfeet with Turco technique. They were classified preoperatively as mild, moderate or severe and grouped into those operated on before or after 1 year of age. All of them underwent serial casting before surgery. We evaluated the functional results by measuring the range of ankle motion and Ponseti score. Results: Out of 56 operated feet, 54 (96\%) feet did not need further treatment. Two feet did recurrence because of noncompliance of parents with orthopedic shoes and physiotherapy. These cases underwent a second surgery and did well. The results were rated, as excellent in $30 \%$ of the feet, good in $50 \%$ of the feet, fair in $16 \%$ of the feet and poor in 4\%. The mean Ponseti score for both groups was 83.9 (good). The younger patients had better results than older patients. Conclusion: Turco technique is effective for the treatment of clubfoot when the conservative treatment has failed. The earlier the intervention is done the better are the functional results.
\end{abstract}

Keyword: Clubfoot, Turco, recurrence, surgery, posteromedial release.

\section{Introduction and Literature Survery}

Congenital talipesequinovarus (clubfoot) is one of the most common birth defects, affecting approximately one in 1000 births $(1,2)$. Its management remains controversial. In recent years, nonoperative treatment has gained popularity especially in developing world. The surgical experience in correcting this condition, however, extends back over 200 years (3). Despite this there are few surgical, long term, follow-up studies. The timing of surgical intervention also remains a dilemma. The majority of surgeons prefer to delay the surgical correction until the patient is over 1 year old. Few advocate early surgery. This paper reports the mid term results of a series of cases using the posteromedial release (Turco) on resistant idiopathic clubfeet and compares the outcomes of feet operated on before the age one year with those operated after one year of age.

\section{Methods}

A prospective case note review revealed 40 patients with 56 affected idiopathic clubfeet. They were operated between 2006 and 2008. All clubfeet were classified at first presentation as mild, moderate or severe. If the foot could be held at or beyond the neutral position the deformity was described as mild. If the foot could not be pushed to neutral and yet the fixed equinus or the angle of varus was estimated at $20^{\circ}$ or less, the deformity was classed as moderate. When the deformity was found to be fixed and greater than $20^{\circ}$ of varus or equinus, it was classed as severe. This closely adhered to the Harrold and Walker classification (4). None were classified as mild in this series, as mild cases responded satisfactory to conservative methods.

A trial of conservative treatment was commenced at the earliest opportunity. This consisted of a combination of serial casting and gentle manipulation of the feet as described by Ponseti (5). Conservative treatment continued until no further progress was made.
All clubfeet in this series underwent a posteromedial release as preferred by the author. This consisted of posteromedial curvilinear incision followed by serial lengthening of the Achilles tendon by $\mathrm{Z}$ plasty then division of tibialis posterior, flexor hallucislongus and flexor digitorumlongus (within their tendon sheaths). If correction was not obtained, capsulotomies of the talo-navicular joint and talo-calcaneal joints were performed. Further release consisted of capsulotomy of the posterior ankle joint, and if at this stage the talo-navicular joint was still not adequately reduced then a lateral release was performed. Postoperatively, the foot was placed in a plaster cast for 6 weeks. The feet were treated then in ankle-foot orthoses. These were worn 23 $\mathrm{h}$ /day for 3 months and then at night only for up to 3 years as clinically indicated. All patients were reviewedat regular intervals and were generally compliant with postoperative regime. Resistant clubfoot with recurrence of deformity or under correction was reoperated on by further posteromedial release.

For this review, the functional outcome rating devised by Laaveg and Ponseti (6) was used. The coauthors independently reviewed all patients. Each parent of child was asked about foot pain, footwear problems, cosmesis of the foot and parent satisfaction with final result. The examination assessed the patients' gait, the position of the heel when standing, passive motion of the ankle joint and foot, calf circumference and foot length. The Laaveg and Ponseti (6) rating system scored each parameter with a grand total of 100 points indicating a normal foot. A score of 90100 points indicated as excellent result, 80-89 a good result, 70-79 a fair result and less than 70 points a poor result. Permission was granted from parents to take digital images of the feet. A radiological assessment was not carried out. Patients were divided into two groups, those who had surgery at less than 1 year of age (group A) and those who had surgery greater than 1 year (group B)

\section{Statistical Methods}




\section{International Journal of Science and Research (IJSR) \\ ISSN (Online): 2319-7064 \\ Index Copernicus Value (2013): 6.14 | Impact Factor (2014): 5.611}

To compare the two groups, the paired t-test as well as the nonparametric Mann-Whitnney U-test was applied. A P value of $<0.05$ was considered significant.

\section{Results}

In all, 40 patients, with 56 clubfeet were enrolled in this study. The minimum length of follow up was 5 years (range $5-7$ years). In all, 24 were male and 16 female. Sixteen patients had bilateral clubfeet. Group A consisted of 20 patients with 24clubfeet. Group B consisted of 20 patients with 32 clubfeet.

Table 1 displays the patient demographics. The results were classified according to the scores described earlier. The results were rated as excellent in $30 \%$ of the feet, good in $50 \%$, fair in $16 \%$ and poor in $4 \%$. Forty-five percent of the patients were never painful, $52 \%$ had occasional mild pain after strenuous activity. Seventy-three percent of parents were very satisfied with end result, $25 \%$ were satisfied and $2 \%$ of parents were never satisfied with end result. No significant difference was seen between the two groups for these values.
Table 1: Patient demographics

\begin{tabular}{|c|c|c|}
\hline & Number of patients $(\mathrm{n}=40)$ & Percentage \\
\hline Sex & 24 & \\
\hline Male & 16 & 60 \\
\hline Female & & 40 \\
\hline Left/right vs.bilateral & 16 & \\
\hline Right & 8 & 40 \\
\hline Left & 16 & 20 \\
\hline Bilateral & Number of Clubfeet $(\mathrm{n}=56)$ & 40 \\
\hline Less than 1 year old & 24 & 43 \\
\hline More than 1 year old & 32 & 57 \\
\hline
\end{tabular}

To correct the deformity 54 of the 56 feet required only one operation and two feet did relapse and required a second surgery. These were two patients of group B and all patients from group A did not required a second surgery.

Figure 1 displays the mean Ponseti outcome scores of all clubfeet in both groups and of those classified as severely affected clubfoot in groups A and B.This suggests that the most severely deformed feet have a better overall outcome if surgical intervention is undertaken before 1 year old despite more frequent need for further posteromedial releases.

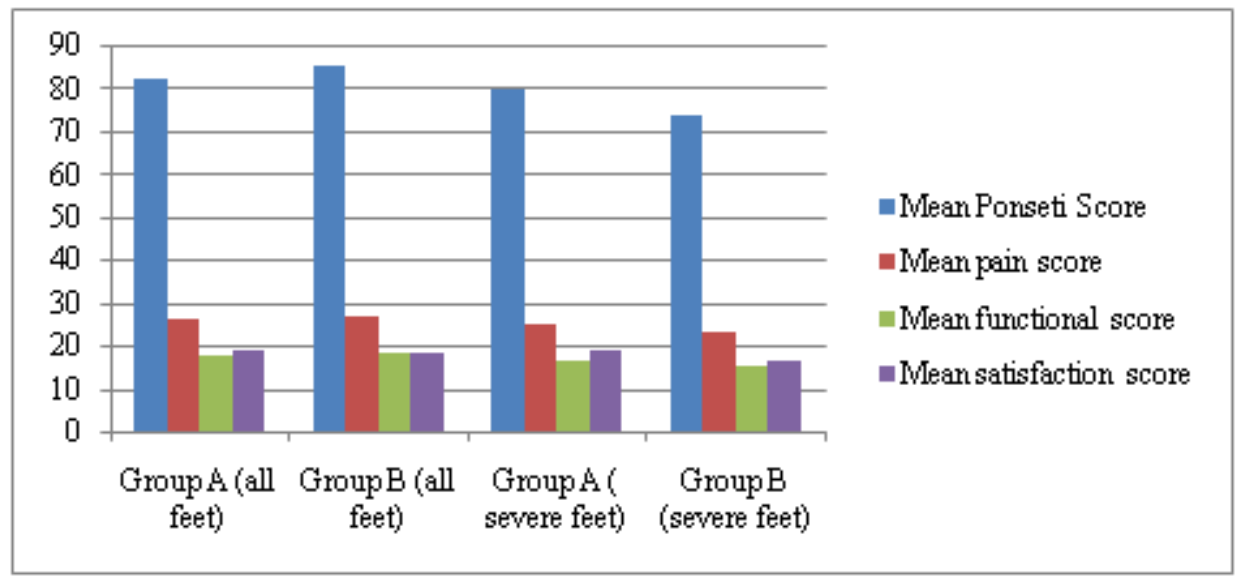

Figure 1: Mean results of the two groups and those classified as severe in the two groups

Figure 2 displays the mean range of motion for the ankle and foot in the two groups. Group B achieved better motion than group A. However, neither group, had a range of motion comparable to a normal foot, especially in dorsiflexion.

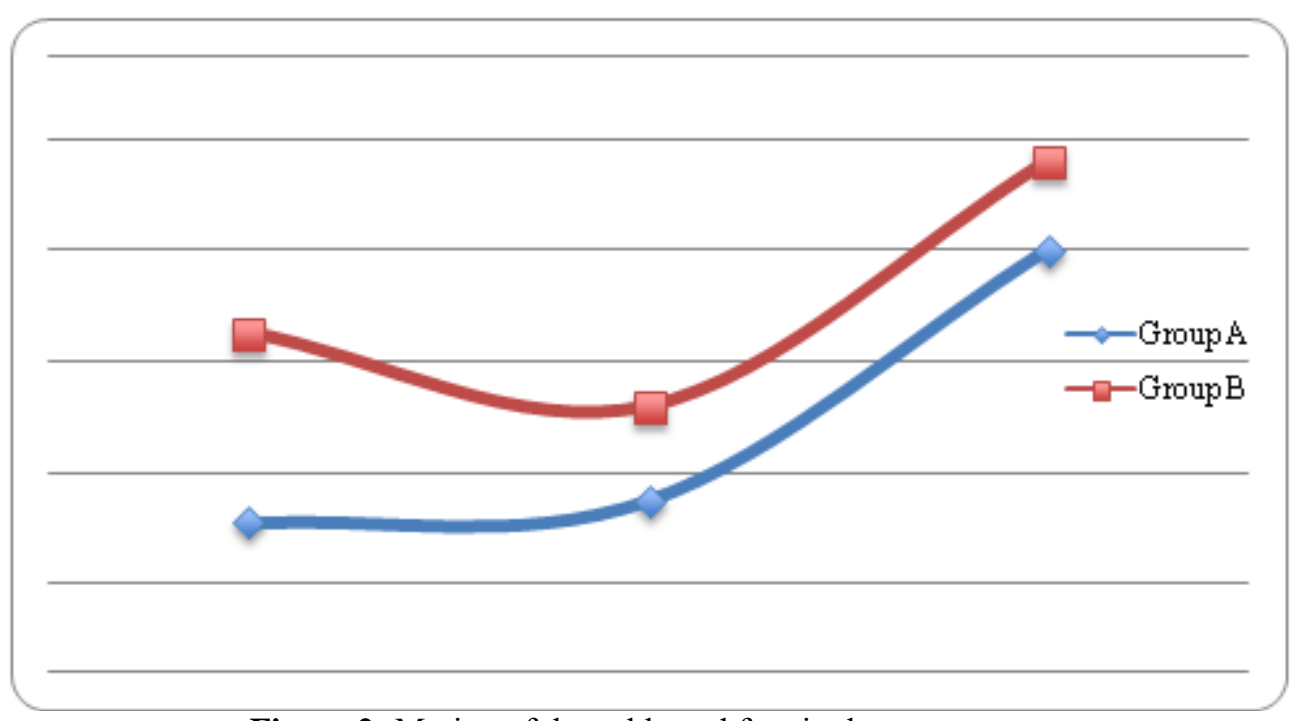

Figure 2: Motion of the ankle and foot in the two groups

Volume 5 Issue 1, January 2016 


\section{International Journal of Science and Research (IJSR) \\ ISSN (Online): 2319-7064}

Index Copernicus Value (2013): 6.14 | Impact Factor (2014): 5.611

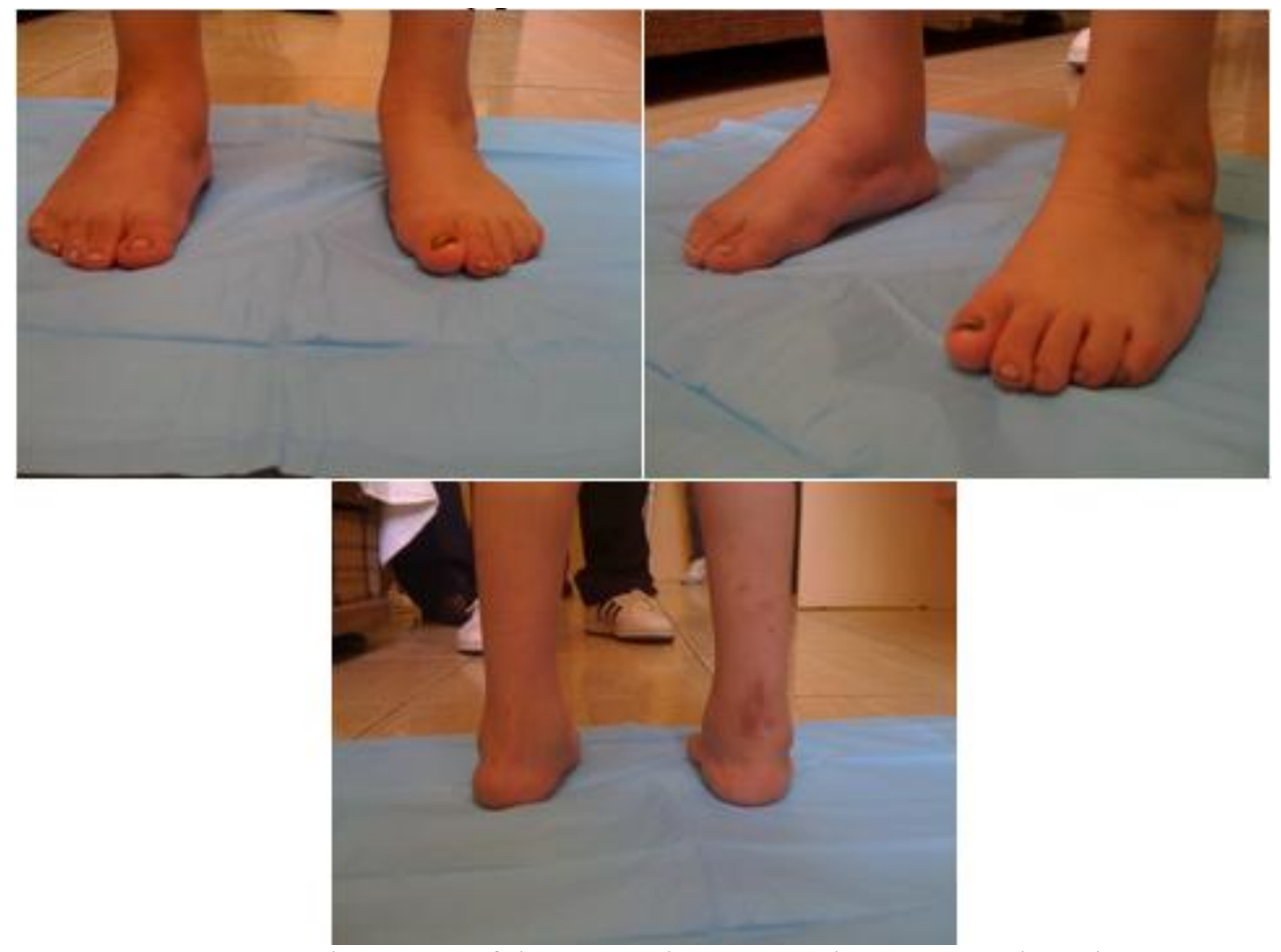

Figure 3: shows one of the cases who was rated as very good result

\section{Discussion}

The ongoing controversy regarding the appropriate treatment of clubfoot has resulted in much variability in practice. Currently there is a trend towards the nonoperative management of this challenging condition. Ponseti (7) has pioneered conservative management with limited operative intervention (percutaneous Achilles tenotomy under local anesthesia). In his hands, a combination of serial casting, with limited operative intervention if required, demonstrated satisfactory results in $89 \%$ of children. Poor results reflected poor technique rather than failure of conservative management (7). A series of studies of long term follow up of conservatively managed clubfoot deformities using the "functional method" as described by Bensahel et al (8) has shown increasingly good results using this nonoperative method, despite the severity of the deformity. This was confirmed by a larger study by Souchet et al (9), in which 350 cases were followed up for mean of 14 years.

Our study examined the mid term outcome of a series of patients who had undergone surgical correction of clubfoot deformity. When asked about satisfaction of parents and pain $98 \%$ of parents were satisfied with the end result $(73 \%$ very satisfied and $25 \%$ satisfied). When asked about pain alone $45 \%$ had no pain and $52 \%$ only occasional pain in their foot. These results compare favorably with other studies $(4,6,7)$.

Our study has shown that early surgical intervention (group A before 1 year old) for the most severe clubfeet may yield better overall results when compared with later intervention (group B after 1 year old). This has, however, been at the expense of requiring several surgical corrections. More surgical correction led to a poorer range of motion in the foot. Hutchins et al (10) studied the 15 year follow-up of
152 clubfeet treated with early surgical correction and although achieving a rate of $81 \%$ good results they also found that poorer range of ankle motion correlated with poor functional results. Another study reinforced this fact with $73 \%$ good results following surgical release for resistant clubfeet (11). Dobbs et al (12) followed up 45 patients with 73 clubfeet who had undergone either a posterior release and plantar fasciotomy or an extensive combined posterior, medial and lateral release. These patients were followed up for 30 years and were evaluated clinically, radiologicaly and with three independent quality of life questionnaires. The study found a correlation between the extent of the soft tissue release and the degree of functional impairment. Repeated soft tissue releases resulted in a stiff, painful, arthritic foot and a patient with a significantly impaired quality of life (12). Few long-term studies of clubfeet treated by surgical release that follow-up patients beyond their teenage years exist $(6,12-15)$. This is a limitation of our study. The oldest patient in our study was 7 years old in the last follow-up. It is the functional outcome of the foot in adulthood that determines the success of surgery in infancy. Despite having poorer range of motion compared with normal feet, our feet still scored highly in the Ponseti rating system. This is because the scoring system uses several subjective criteria to score the feet including: pain, limitation to activities and being able to walk on a flat sole.

Other limitations to our study exist. First, there is a small sample size, an unfortunate consequence of mid-term follow-up. Second, the rating system used depended a great deal on the parent's subjective responses. Third, the preoperative rating system used was neither recognized not validated but did seem to closely resemble the one described by Harrold and Walker (4). Fourth, a radiograph evaluation of the clubfeet was not carried out. We decided not to use XRay because of growing body of evidence has shown that traditional radiographic endpoints do not reflect patient-

\section{Volume 5 Issue 1, January 2016}




\section{International Journal of Science and Research (IJSR) \\ ISSN (Online): 2319-7064}

Index Copernicus Value (2013): 6.14 | Impact Factor (2014): 5.611

based outcomes after clubfoot surgery $(6,13,16$ - 18). It, however, would have been useful to determine whether any arthritis was developing. Finally, although Achilles length was not formally assessed, walking on tip toes was required as part of the Ponseti functional rating system we used to score the feet of all our patients; only the few with the very lowest scores were unable to do this.

Many studies report that the best result for clubfoot surgery occur when surgery is performed at an early age (19-23). Otremski et al (21) found that the necessity for bony procedures at repeat surgery was in those feet treated surgically before 6 months of age. Green and Lloyd-Roberts (23) found that the older the patients after 5 months of age, the worse the surgical outcome. Cummings and Lovell (24) stated that when surgery was performed before 2 months of age there was no improvement in outcome over a later age. One author preferred to wait until the foot was greater or equal to $8 \mathrm{~cm}$ in length before contemplating surgery (25). Some authors have stated that there is no correlation between functional outcome and the age at which surgery is performed $(15,26)$.

Our study suggests that patients achieve a good functional outcome with surgical correction before 1 year of age. Our results indicate improved outcomes for those operated on younger that 1 year old when their deformity is severe, compared with those operated on or after the age of 1 year (Ponseti rating 80.2 vs. 73.8 respectively). Statistical analysis using the paired t-test and Mann-Whitney U-test revealed that there was no significant difference between the two groups $(\mathrm{P}>0.05)$. Furthermore, with regards to parent satisfaction and pain scores there appeared to be no significant difference between the two groups.

Importantly, however, our data suggest there is a trend toward better outcomes if severely deformed feet are operated before 1 year of age (Group A) when compared with those operated later than the age 1 year old (Group B). We feel that the results were not statistically significant owing to the small sample size; however, we are encouraged by our results of surgical correction of severely affected clubfeet.

\section{References}

[1] Cowell HR, WeinBK.Current concepts in review: genetic aspects of clubfoot. J Bone Joint Surg (Am) 1980; 62: 1381

[2] DanielssonLG.Incidence of congenital clubfoot in Sweeden:128 cases in 138000 infants, 1946-1990, in Malmo.ActaOrthopScand 1992; 63: 424

[3] Kuhlamnn RF.A clinical evaluation of operative procedures for congenital talipesequinovarus. ClinOrthop 1972; 84:88

[4] Harrold AJ, Walker CJ.Treatment and prognosis in congenital clubfoot.J Bone Joint Surg (Br) 1983; 65-B: 8-11

[5] Ponseti

R.CummingsRJ,DavidsonRS,ArmstrongPF,Lehman

WB (2002) The Ponseti Technique for Correction of Congenital Clubfoot J. Bone Joint Surg. Am., 84: 1889 $-1891$
[6] Laaveg SJ, PonsetiIV.Long-term results of treatment of congenital clubfoot.J Bone Joint Surg 1980; 62-A: 2331.

[7] Ponseti IV.Treatment of congenital clubfoot J. Bone Joint Surg. Am 1992; 74: 448 - 454.

[8] Bensahel H, Jahanno P, Delaby JP, Themar-Noel C. Conservative treatment of clubfoot: the functional method and its long-term follow-up.ActaOrthopaedica et TraumatologicaTurcica 2006; 40: 181-186 (in Turkish).

[9] Souchet P, Bensahel H, Themar-Noel C, Pennecot G, Csukonyi Z. Functional treatment of clubfoot: a new series of 350 idiopathic clubfeet with long-term followup. J PaediatrOrthop B 2004; 13: 189-196

[10] Hutchins P, Foster BK, Paterson DC, Cole EA.Longterm results of early surgical release in clubfeet. J Bone Joint Surg 1985; 67-B: 791-799.

[11] Bensahel H, Csukonyi Z, Desgrippes Y, Chaumien JP. Surgery in residual clubfoot: one-stage medioposterior release "a la carte". J PaediatrOrthop 1987; 7: 145-148.

[12] Dobbs MB, Nunley R, Schoenecker PL. Long-term follow-up of patients with clubfeet treated with extensive soft-tissue release. J Bone Joint Surg Am 2006; 88: 986-996.

[13] Ippolito E, Farsetti P, Caterini R, Tudisco C. Long-term comparative results in patients with clubfoot treated with two different protocols. J Bone Joint Surg Am 2003; 85: 1286-1294.

[14] Copper DM, Dietz FR. Treatment of idiopathic clubfoot.A thirty year follow-up note. J Bone Joint Surg Am 1995; 77: 1477-1489.

[15] Hutchins P, Foster BK, Paterson DC, Cole EA.Longterm results of early surgical release in clubfeet. J Bone Joint Surg 1985; 67-B: 791-799

[16] Wener DR, Rang M. The art and practice of childrensorthopaedics. New York: Raven Press; 1993. pp. 138-165.

[17] Herbsfother B, Eckhardt A, Rompe JD, Kullmer K. Significance of radiographic angle measurements in evaluation of congenital clubfoot. Arch Orthop Trauma Surg 1998; 117: 324-329.

[18] Vitale MG, Choe JC, Vitale MA, Lee FY, Hyman JE, Roye DP Jr. Patient-based outcomes following clubfoot surgery - A 16 year follow-up study. J PediatrOrthop 2005; 25: 533-538.

[19]Porat S, Milgrom C, Bentley G. The history of treatment of congenital clubfoot at the Royal Liverpool Childrens Hospital: improvement of results by early extensive posteromedial release. J PediatrOrthop 1984; 4: 331-338.

[20] Tarraf Y, Carroll N. Analysis of the components of residual deformity in clubfeet presenting at reoperation. J PediatrOrthop 1992; 12: 207-216.

[21] Otremski I, Salama R, Khermosh O, Weintraub S. An analysis of the results of a modified one stage posteromedial release (Turco operation) for the treatment of clubfoot. J PediatrOrthop 1987; 7: 149151.

[22] DeRossa G, Stepro D. Results of posteromedial release for resistant clubfoot. J PediatrOrthop 1986; 6: 590-595

[23] Green AD, Lloyd-Roberts GC.The results of early posterior release in clubfeet. J Bone Joint Surg 1985; 67B: 588-593. 


\section{International Journal of Science and Research (IJSR) \\ ISSN (Online): 2319-7064}

Index Copernicus Value (2013): 6.14 | Impact Factor (2014): 5.611

[24] Cummings RJ, Lovell WW. Current Concepts review of operative treatment of congenital idiopathic clubfoot. J Bone Joint Surg 1988; 70A: 1108-1112.

[25] Simons GW. Complete subtalar release in clubfeet.II. Comparison with less extensive procedures. J Bone Joint Surg 1985; 67A: 1056-1065.

[26] Ghali NN, Smith RB, Clayden AD, Silk FF.The results of pantalar reduction of congenital talipesequinovarus. $\mathrm{J}$ Bone Joint Surg 1983; 65B: 1-7. 